\title{
Lipodystrophy and Associated Factors In Haart Receiving HIV Subjects In Sodo Town, Ethiopia
}

\author{
${ }^{1,2}$ Vedavalli Sachithananthan,Ph.D., ${ }^{2}$ Eskinder Loha,M.Sc., ${ }^{2}$ Mesfin Gose, M.Sc \\ ${ }^{1}$ Department of Clinical nutrition, College of Applied medical sciences, University of Hail, Saudi Arabia \\ ${ }^{2}$ Institute of Nutrition, food science and technology, Hawassa University, Ethiopia
}

\begin{abstract}
Ethiopia is one of the countries in Africa with a high prevalence of HIV/AIDS. Though the introduction of highly active antiretroviral therapy (HAART) improved survival and quality of life, early data from those treated, raised concerns about a possible increase in both peripheral and coronary arterial disease through lipodystrophy, diabetes mellitus and dyslipidemia. Hence an attempt was made in this study to assess the prevalence of lipodystrophy and to understand risk factors in HIV positive subjects receiving HAART. Study participants were men and women who were HIV/AIDS patients receiving HAART from Sodo government hospital, Southern Ethiopia. Data was collected on sociodemographic characteristics, HAART use, CD4 count, and subjects' status at the start of treatment, measure of body fat distribution and physical activity. In the present study the prevalence of moderate to severe clinical lipodystrophy in HIV-infected subjects receiving HAART for atleast 6 months was 15.9\%, lipoatrophy was $9.1 \%$ and lipohypertrophy was $6.8 \%$. Subjects who had been on HAART for 4 yrs or more, engaged in much lighter work intensity and who were underweight and overweight or obese had higher prevalence of lipodystrophy. In multivariate analysis, gender, duration of HAART, work intensity and recent BMI remained significantly associated with overall lipodystrophy. In multivariate analysis, for phenotypes of lipodystrophy, only work intensity remained significantly associated with lipoatrophy whereas work intensity and duration of HAART remained significantly associated with lipohypertrophy. Lipohypertrophy and lipoatrophy were positively associated with diabetes mellitus, while only lipohypertrophy was associated with hypertension. None of the HAART drugs or regimens were significantly associated with lipodystrophy and diabetes mellitus. Lipodystrophy syndrome has severe health consequences, as it may be responsible for stigma, reduced adherence to antiretroviral treatment, and increased risk of cardiovascular diseases.
\end{abstract}

Key words: lipodystrophy - associated factors - HIV - highly active antiretroviral therapy (HAART)

\section{Introduction}

Ethiopia is one of the countries in Africa with a high prevalence rate of HIV/AIDS. At the end of 2005 a total of 1.3 million adults and children were living with HIV/AIDS. In the same year alone there were an estimated 1,28,900 new HIV infections and 1,34,500 AIDS deaths. Life expectancy is falling as a result of the epidemic and is expected to drop to 50 years by 2010 from a previous estimate of 59 years. The Government of Ethiopia planed to avail a universal access to anti retroviral therapy (ART) to reduce AIDS deaths by $41 \%$ by 2010 (FMOH 2005)(10). Consequently, at the end of February 2009, 1,36,344 patients nationally and 845 patients at Sodo Hospital, are currently receiving highly active antiretroviral therapy (HAART) (FMOH, 2009) (9).The introduction of highly active antiretroviral therapy (HAART) revolutionized the prognosis of HIV/AIDS. However, the use of such treatment regimen has coincided with the emergency of body fat distribution modification (lipodystrophy) (Andrew, et al., 2003)(1). Lipodystrophy is defined as fat loss (lipoatrophy) at peripheral body sites (face, arms, legs, and buttocks) and/or fat gain (lipohypertrophy) at central body sites (dorsocervical area and abdomen). When lipodystrophy is accompanied by metabolic alterations such as insulin resistance and/or hyperdyslipidemia it is termed as lipodystrophy syndrome (LS) (Carr, et al., 1998)(6).

This problem is of a great concern for HIV infected individuals who are on ART, as they are at an increased risk of chronic diseases like cardiovascular diseases (Andrew, et al., 2003)(1). The prevalence of lipodystrophy widely varies from $2 \%$ to $83 \%$ because of the use of different measures and definitions of lipodystrophy (Tien et al., 2004)(17). An Australian cross-sectional study reported an overall prevalence of lipodystrophy in $53 \%$, a mixed type was seen in 55\%, only peripheral lipoatrophy in $31 \%$ and central lipohypertrophy in $14 \%$ of HAART receiving HIV patients (Miller, et al., 2003)(15).

The definite cause of HIV associated lipodystrophy and metabolic alteration is unknown. However, different researchers reported different risk factors associated with the development of the problem. The toxic effect of the drug, life style (physical activity, smoking, and alcohol use), diet, age and ethnicity are some of the factors so far reported (Hadigan, 2003)(13). 
Therefore, this study aims to determine the prevalence of lipodystrophy, and the factors associated with this problem among HIV positive subjects receiving HAART at Sodo hospital.

\section{Materials And Methods}

Welayita Sodo is the zonal town of Welayita ethnic group found in Southern Nations and Nationalities Peoples Region (SNNPR), South of Ethiopia, $350 \mathrm{~km}$ away from the capital, Addis Ababa. It has a total of 75,000 residents mostly of Welayita. The town has one government, two non government hospitals and one health center. Government supported free HIV/AIDS care including HAART was delivered in all of these institutions. Institution based cross-sectional and retrospective study was conducted from December $1^{\text {st }}, 2009$ January $30^{\text {th }}, 2011$.

Study participants were men and women who were HIV/AIDS patients receiving HAART from Sodo government hospital, Southern Ethiopia. Patients were excluded if they had any active opportunistic infections in the past 3 months, were on any anabolic or corticosteroid agents, if pregnant or using hormonal contraceptives, if the subject was critically ill and unable to undergo the assessment and had a family history of hypertension and /or diabetes mellitus. Subjects were included in the study if they were between the age of 18 and 50 years, had documented HIV infection, and were on HAART for $>6$ months. Study subjects were screened by review of the subjects' health record and by interviewing using structured screening questions. By using the subjects' electronic database as sampling frame, a total of 176 subjects were recruited for the study using simple random sampling method. For estimation of the number of patients with lipodystrophy to be selected for this study, data from Rwandan study done by Mutimura and his colleagues (Mutimura, et al., 2007)(16)was utilized. In this study they reported lipodystrophy prevalence of $34 \%$.

Data was collected on sociodemographic characteristics such as age, sex, ethnicity, religion, educational status, residence, income and functional status at the start of treatment was included and collected by interview.

From the patient's health record, data on CD4 count at the start of treatment and in the last 6 months, stage of disease at the start of treatment, type and duration of HAART used in the last 3 months from the study period and weight at start of treatment were collected.

Body fat distribution was assessed by patient's self report and physical examination done by a physician. Using a lipodystrophy specific standardized questionnaire, trained physicians working in the clinic determined whether participants had more or less fat than healthy people in each of the same body areas as questioned during the interview. These data were used to assess the agreement between both lipodystrophy assessment methods.

The primary outcome was physician reported lipodystrophy at the time of examination. It was defined as a finding of moderate or severe change in any of the following parameters: fat loss in the face or arms; fat gain in the back or base of the neck; increase in breast size; decrease in fat on buttocks or legs; or lipomatosis. The presence of lipodystrophy was based on a subjective case definition previously developed and validated by Carr and his colleagues (Carr, et al., 2003)(5) but excluded clinical characteristics not generally recognized as manifestations of HIV associated lipodystrophy (i.e., fat gain in face, fat loss/gain in the front or sides of neck, fat gain in arms, decrease in breast size, increase in fat on buttocks or legs, and decrease in waist size). Consistent with the definition by Carr and his colleagues (Carr, et al., 2003)(5), patients reporting "moderate or severe isolated abdominal obesity" were excluded from analysis in order to avoid confounding by age-related central adiposity. The phenotypes of lipodystrophy were also examined: lipohypertrophy (defined as a response of moderate or severe fat gain in the back or base of the neck or increase in size of breast); lipoatrophy (defined as a response of moderate or severe fat loss in the face or arms, or decrease in fat on buttocks or legs); and reporting both fat gain (i.e., lipohypertrophy or lipomatosis) and fat loss (i.e. lipoatrophy) after the diagnosis of HIV infection.

The height and body weight were measured to a precision of $0.1 \mathrm{~cm}$ and $0.1 \mathrm{~kg}$, respectively, utilizing a digital balance and height measurement attached to the digital balance.

Body mass index (BMI) was calculated as a ratio between the weight in kilograms and the square of the height in meters (Gibson, 2005)(12).

Health workers from the study hospital measured resting blood pressure using an automated sphygmomanometer according to a standardized protocol (Perloff, et al., 1993). Values of blood pressure greater than $140 / 90 \mathrm{mmHg}$ were considered to be hypertensive.

Diagnosis of diabetes mellitus was made based on a single fasting blood glucose test using finger prick by enzymatic method (WHO, 2003). Blood levels greater than or equal to $126 \mathrm{~g} / \mathrm{dl}$ were considered to be diabetic.

To evaluate the habitual physical activity, data on physical activity was collected using the questionnaire devised by Baecke and coworkers (Baecke et al., 1982)(3). However, because of a few number of subjects who had the habit of leisure time physical exercise and regular physical exercise, level of physical 
activity was determined based on the subjects self labeling of their work intensity according to their age. Thus, subjects rated their work intensity as 'much heavier', 'equally heavier' and 'much lighter'.

Bivariate analysis was used to identify significant predictors of lipodystrophy. Independent variables showing significant association $(\mathrm{p}=0.05)$ during bivariate analysis were fed into multivariate models to control for confounding variables and analyzed using multivariate logistic regression.

Because only few number of subjects had the habit of alcohol use, smoking and physical exercise, these factors were not tested for association with dependent variables. All significant test values were two sided and significant values considered at $\mathrm{p}=0.05$. Analysis was performed using SPSS version 12 .

\section{Ethical considerations}

Ethical approval was obtained from Hawassa University Ethical board. The study participants consented to participate in the study.

\section{Prevalence of lipodystrophy}

\section{Results}

In the present study the prevalence of moderate to severe clinical lipodystrophy in HIV-infected subjects receiving HAART for atleast 6 months was $15.9 \%$. Lipoatrophy was $9.1 \%$ and lipohypertrophy was $6.8 \%$.

\section{Lipodystrophy-associated factors}

The participants of the present study were different in some health related behaviors from the participants of other studies. There were very little number of subjects $(1.1 \%)$ who were smoking cigarettes or drinking alcohol. The habit of regular physical activity was reported only in $9.1 \%$ of subjects. Hence these factors were not studied for their association with lipodystrophy and the HAART regimen.

TABLE la: Factors Associated With Overall Lipodvstrophy Of Haart Receiving Hiv Subjects

\begin{tabular}{|c|c|c|c|c|c|}
\hline \multicolumn{2}{|c|}{ Characteristics } & $\mathrm{N}$ & $\begin{array}{l}\mathrm{LD} \\
\mathrm{n}(\%)\end{array}$ & COR $(95 \% \mathrm{CI})$ & $\mathrm{AOR}(95 \% \mathrm{CI})$ \\
\hline \multicolumn{2}{|r|}{ Total subjects } & 176 & $28(15.9)$ & & \\
\hline \multirow[t]{2}{*}{ Age, yr } & $<40$ & 128 & $20(11.4)$ & 1 & \\
\hline & $\geq 40$ & 48 & $8(4.5)$ & $1.1(0.4-2.6)$ & \\
\hline \multirow[t]{2}{*}{ Sex } & Male & 86 & $6(3.4)$ & 1 & 1 \\
\hline & Female & 90 & $22(12.5)$ & $4.3(1.6-11.2)^{*}$ & $6.1(1.4-25.9)^{*}$ \\
\hline \multirow[t]{2}{*}{ Ethnicity } & Wolayita & $140^{-}$ & $21(11.9)$ & 1 & \\
\hline & Others & 36 & $7(4.0)$ & $1.4(0.5-3.5)$ & \\
\hline \multirow[t]{2}{*}{ Income } & $<600$ & 148 & $23(13.1)$ & 1 & \\
\hline & $\geq 600$ & 28 & $5(2.8)$ & $1.2(0.4-3.4)$ & \\
\hline \multirow{3}{*}{$\begin{array}{l}\text { Functional } \\
\text { Status } \\
\text { (Baseline) }\end{array}$} & Working & $70^{-}$ & $9(5.1)$ & 1 & \\
\hline & Ambulatory & 10 & $1(0.7)$ & $0.7(0.02-6.7)$ & \\
\hline & Bed ridden & 96 & $18(10.2)$ & $1.6(0.6-4.1)$ & \\
\hline \multirow{2}{*}{$\begin{array}{l}\text { Duration of } \\
\text { HAART, } \\
\text { yr }\end{array}$} & $<4 \mathrm{yrs}$ & 136 & $16(9.1)$ & 1 & 1 \\
\hline & $\geq 4 \mathrm{yrs}$ & 40 & $12(6.8)$ & $3.2(1.368-7.55)^{*}$ & $9.03(2.2-36.4) *$ \\
\hline
\end{tabular}

In bivariate analysis, sociodemographic characteristics such as age, religion, occupation, income and marital status were not associated with moderate-severe clinical lipodystrophy $(\mathrm{p}=0.05)$, whereas only gender was found to have significant association. Women had a higher prevalence of lipodystrophy than men (Table 1a).

Clinical characteristics which showed significant associations with moderate-severe clinical lipodystrophy were duration of HAART, work intensity, and recent BMI. Subjects who had been on HAART for 4 yrs or more, engaged in much lighter work intensity and who were underweight and overweight or obese had higher 
prevalence of lipodystrophy. CD4 count before HAART and recent, functional status and disease stage before HAART were not associated with lipodystrophy (Table1a and b).

TABLE 1b: Factors Associated With Overall Lipodvstrophy Of Haart Receiving Hiv Subjects

\begin{tabular}{|c|c|c|c|c|c|}
\hline \multicolumn{2}{|c|}{ Characteristics of subjects } & $\mathrm{N}$ & $\begin{array}{l}\text { I-ipodystrophy } \\
\text { n }(\%)\end{array}$ & COR $(95 \%$ CI $)$ & AOR $(95 \% C I)$ \\
\hline \multicolumn{2}{|c|}{ Total subjects } & 176 & $28(15.9)$ & & \\
\hline \multirow{2}{*}{$\begin{array}{l}\text { baseline } \\
\text { bas }\end{array}$} & $<350^{\circ}$ & $16 \overline{6}$ & $26(14.8)$ & 1 & \\
\hline & $\geq 350$ & 10 & $2(1.1)$ & $1.3(0.3-6.7)$ & \\
\hline \multirow{2}{*}{$\begin{array}{l}\text { recent } \\
\text { rend }\end{array}$} & $<350$ & 94 & $12(6.8)$ & 1 & \\
\hline & $\geq 350$ & 72 & $16(9.1)$ & $1.7(0.7-3.7)$ & \\
\hline \multirow{3}{*}{$\begin{array}{l}\text { Work } \\
\text { intensity }\end{array}$} & Much heavier & 78 & $4(2.3)$ & 1 & 1 \\
\hline & As heavy & 44 & $4(2.3)$ & $1.8(0.3-10.4)$ & $4.1(0.7-22.3)$ \\
\hline & Much lighter & 54 & $20(11.4)$ & $10.9(3.2-46.3)^{*}$ & $19.5(4.2-91.9)^{*}$ \\
\hline \multirow{3}{*}{$\begin{array}{l}\text { baseline } \\
\text { baselin }\end{array}$} & Under weight & $60^{-1}$ & $10(5.7)$ & $1.6(0.6-4.4)$ & \\
\hline & $\begin{array}{l}\text { Normal } \\
\text { weight }\end{array}$ & $110^{-}$ & $12(6.8)$ & 1 & \\
\hline & $\begin{array}{l}\text { Overweight } \\
\text { and Obese }\end{array}$ & 6 & $6(3.4)$ & - & \\
\hline \multirow{3}{*}{$\begin{array}{l}\text { Becent } \\
\text { recen }\end{array}$} & Underweight & 26 & $10(5.7)$ & 1 & 1 \\
\hline & $\begin{array}{l}\text { Normal } \\
\text { weight }\end{array}$ & 136 & $12(6.8)$ & $0.15(0.05-0.5)^{*}$ & $0.04(0.01-0.12)^{*}$ \\
\hline & $\begin{array}{l}\text { Overweight } \\
\text { and Obese }\end{array}$ & 14 & $6(3,4)$ & $1.2(0.3-5.5)$ & $0.1(0.01-0.97)$ \\
\hline
\end{tabular}

$p_{p}=0.05, N=$ number of subjects

Multivariate models of logistic regression were further tested to identify the independent effect of the different covariates. Gender, duration of HAART, work intensity and recent BMI remained significantly associated with overall lipodystrophy (Table 1a and 1b).

\section{Factors associated with lipoatrophy and lipohypertrophy}

In bivariate analysis, lipoatrophy was significantly associated with recent BMI and work intensity (Table 2), whereas lipohypertrophy was significantly associated with ethnicity, recent BMI, work intensity, recent CD4 count and duration of HAART (Table 3).

\begin{tabular}{|c|c|c|c|c|c|}
\hline \multicolumn{2}{|c|}{ Subjects' characteristics } & \multirow{2}{*}{$\begin{array}{l}15 \\
176\end{array}$} & \multirow{2}{*}{$\begin{array}{c}\begin{array}{c}\text { Prevalence of } \\
\text { lipoatrophx ( }\end{array} \\
14 \% \text { ) }\end{array}$} & \multirow[t]{2}{*}{$\mathrm{COR}(\mathrm{CI})$} & \multirow[t]{2}{*}{$\mathrm{AOR}(95 \% \mathrm{CI})$} \\
\hline Total & & & & & \\
\hline \multirow[t]{2}{*}{ Age, yr } & $<40^{-}$ & $12 \overline{8}$ & $12(\overline{6} .8)$ & $\overline{1}^{-}$ & \\
\hline & $\geq 40^{-}$ & 48 & $4(2.3)$ & $0.9(0.2-3.2)$ & \\
\hline \multirow[t]{2}{*}{$\operatorname{sex}$} & Male & $8 \overline{6}$ & $6(3.4)$ & 1 & \\
\hline & Fermale- & $90^{-1}$ & $10(5.7)$ & $2.0(0 . \overline{6}-\overline{6} .9)$ & \\
\hline \multirow{2}{*}{$\begin{array}{l}\text { Duration of } \\
\text { HA_ART, yx }\end{array}$} & $<4 \mathrm{yrs}^{2}$ & $13 \overline{6}$ & $12(\overline{6} .8)$ & 1 & \\
\hline & $\geq 4$ yrs & $40^{--}$ & $4(2.3)^{--}$ & $1.43(0.3-5.2)$ & \\
\hline \multirow[t]{2}{*}{ CD4 baseline } & $<350^{-1}$ & $16 \overline{6}$ & $14(7.9)$ & 1 & \\
\hline & $\geq 350^{-1}$ & $10^{--}$ & $2(1.1)$ & $2.5(0.23-14.3)$ & \\
\hline \multirow[t]{2}{*}{ CD4 recent } & $<350$ & 94 & $10(5.7)$ & 1 & \\
\hline & $\geq 350^{-\cdots}$ & $7 \overline{2}$ & $6(3.4)$ & $0.75(0.2-2.4)$ & \\
\hline \multirow{3}{*}{$\begin{array}{l}\text { Work } \\
\text { intensity }\end{array}$} & Much heavier & $-78^{-}$ & $\overline{2}(\overline{1} \cdot \overline{1})$ & $\overline{1}^{-\cdots-\cdots}$ & $0.04(0.005-0.3) 4$ \\
\hline & As heavy & 44 & $4(2.3)$ & $3.7(0.5-42.1)$ & $0.3(0.07-1.4)$ \\
\hline & Much lighter & $-54^{-}$ & $10(5.7)$ & $10.9(2.1-105.3)^{\circ}$ & $\overline{1}^{-\cdots-\cdots-}$ \\
\hline \multirow[t]{3}{*}{ BMII baseline } & Under weight & $60^{-}$ & $10(5.7)$ & $3.3(1.0-11.5)$ & \\
\hline & $\begin{array}{l}\text { Nominal } \\
\text { weight }\end{array}$ & $110^{-1}$ & $6(3.4)$ & $\overline{1}^{-\cdots-\cdots}$ & \\
\hline & $\begin{array}{l}\text { Overueight } \\
\text { and Obese }\end{array}$ & 6 & $0(0.0)$ & - & \\
\hline \multirow[t]{3}{*}{ BMII recent } & Underveight & 26 & $10(5.7)$ & 1 & $=$ \\
\hline & $\begin{array}{l}\text { Nommal } \\
\text { weight }\end{array}$ & $13 \overline{6}^{-}$ & $6(3.4)$ & $0.08(0.02-0.27)$ & - \\
\hline & $\begin{array}{l}\text { Overueight } \\
\text { and Obese }\end{array}$ & 14 & $0(0.0)$ & $0.0(0.0-1.2)$ & - \\
\hline
\end{tabular}


Lipodystrophy And Associated Factors In Haart Receiving HIV Subjects In Sodo Town, Ethiopia

TABLE 3: Factors Associated With Overall Iipohxpertxophx, Qf Haart Receiving Hix Subjects

\begin{tabular}{|c|c|c|c|c|c|}
\hline \multicolumn{2}{|c|}{ Subjects" characteriatica } & $\mathrm{N}$ & $\begin{array}{c}\text { Prevalence } \\
\text { of LH }\end{array}$ & COR $(95 \% 6 \mathrm{CI})$ & $\mathrm{AOR}(9596 \mathrm{CI})$ \\
\hline \multicolumn{2}{|c|}{ Total subjects } & 176 & $12(6.8)$ & & \\
\hline \multirow[t]{2}{*}{ Age, yx } & $<40^{-}$ & $12 \overline{8}$ & $8(4.5)$ & $\overline{1}$ & \\
\hline & $\geq 40$ & 48 & $4(2.3)$ & $1.35(0.3-5.4)$ & \\
\hline \multirow[t]{2}{*}{ Sex } & Male & 86 & $0(\overline{0} . \overline{0})$ & $0.0(0.0-0.3)^{4}$ & - \\
\hline & Fermale & $90^{-}$ & $1 \overline{2}(\overline{6} . \overline{8})$ & $\overline{1}^{-\cdots-\cdots}$ & 1 \\
\hline \multirow[t]{2}{*}{ Ethnicity } & Wolaxita & $140^{-}$ & $5 \overline{(2.8)}$ & $0.2(0.04-0.7)^{4}$ & $1.03(0.16-6.5)$ \\
\hline & Other: & $3 \overline{6}^{-1}$ & $7(4.05)$ & 1 & $\mathrm{I}^{-\cdots---}$ \\
\hline \multirow[t]{2}{*}{ Income } & $<600^{-}$ & $\overline{1} 4 \overline{8}$ & $7(4.0)$ & 1 & \\
\hline & $\geq 600^{-}$ & 28 & $5(2.8)$ & $3.9(0.9-15.5)$ & \\
\hline \multirow{3}{*}{$\begin{array}{l}\text { Functional } \\
\text { Status } \\
\text { (Baseline) }\end{array}$} & Working & $70^{-1}$ & $3(1.7)$ & 1 & \\
\hline & Ambulatory & 10 & $1(0.6)$ & $2.3(0.04-31.5)$ & \\
\hline & Bed ridden & $9 \overline{6}^{-}$ & $8(4.5)$ & $2.1(0.5-12.7)$ & \\
\hline \multirow{2}{*}{$\begin{array}{l}\text { Duration of } \\
\text { H.A.ART, yx }\end{array}$} & $<4 \mathrm{yrg}^{-}$ & $13 \overline{6}$ & $4(2.3)$ & $0.1(0.02-0.5)^{4}$ & $0.03(0.001-0.6)^{4}$ \\
\hline & $\geq 4$ yrs & $40^{-}$ & $8(4.5)^{-}$ & 1 & $\overline{1}^{--\cdots+-\cdots}$ \\
\hline \multirow{2}{*}{$\begin{array}{l}\text { CD4 } \\
\text { baseline }\end{array}$} & $<350^{--}$ & $1 \overline{6} \overline{6}$ & $12(6.8)$ & $\overline{1}^{-\cdots-\cdots}$ & \\
\hline & $\geq 350$ & $10^{-}$ & $0(\overline{0} . \overline{0})$ & $0.0(0.0-7.8)$ & \\
\hline \multirow[t]{2}{*}{$\overline{C D} 4$ recent } & $2350^{\circ}$ & 94 & $2(1.1)$ & $0.16(0.02-0.8)^{4}$ & $0.3(0.03-3.7)$ \\
\hline & $\geq 350$ & 72 & $10 \times 5.79$ & 1 & 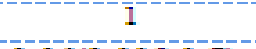 \\
\hline \multirow{3}{*}{$\begin{array}{l}\text { WVork } \\
\text { intensity }\end{array}$} & Much heavier & 78 & $2(\overline{1} \cdot \overline{1})$ & $0.1(0.01-0.5)$ & $0.06(0.005-0.7)^{4}$ \\
\hline & As heavy & 44 & $0(0.0)$ & $0.0 \times 0.0-0.4)^{4}$ & - \\
\hline & Much lighter & 54 & $10(5.7)$ & $\overline{1}^{-\cdots---}$ & $\overline{1}$ \\
\hline \multirow{3}{*}{$\begin{array}{l}\text { BMII } \\
\text { baseline }\end{array}$} & Under weight & $60^{-1}$ & $0(0.0)$ & $0.0 \times 0.0-1.79$ & \\
\hline & Somal weight & $1 \overline{1}$ & $6(3 . \overline{4})$ & $\overline{1}^{--1-0-1}$ & \\
\hline & $\begin{array}{l}\text { Overveight and } \\
\text { Obese }\end{array}$ & $-\overline{6}^{--}$ & $6(3.4)$ & - & \\
\hline \multirow[t]{3}{*}{ BMII recent } & Underveight & $2 \overline{6}^{-}$ & $0,(0.0)$ & $0.0(0.0-0.6)^{4}$ & 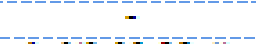 \\
\hline & Somal weight & 136 & $6(3.4)$ & $0.06(0.01-0.3)^{4}$ & $1.6(0.09-28.4)$ \\
\hline & $\begin{array}{l}\text { Overweight and } \\
\text { Obese }\end{array}$ & 14 & $6(3.4)$ & 1 & 1 \\
\hline
\end{tabular}

In multivariate analysis, for phenotypes of lipodystrophy, only work intensity remained significantly associated with lipoatrophy (Table 2) whereas work intensity and duration of HAART remained significantly associated with lipohypertrophy (Table 3). None of the HAART drugs or regimens were significantly associated with lipodystrophy.

\section{Association of diabetes mellitus and hypertension with lipodystrophy}

In multivariate analysis adjusted for age and duration of HAART both lipoatrophy and lipohypertrophy were significantly associated with diabetes mellitus while only lipohypertrophy (adjusted for age) remained to be significantly associated with hypertension. None of the HAART drugs or regimens were significantly associated with diabetes mellitus or hypertension.

\section{Discussion}

In the present study the prevalence of moderate to severe clinical lipodystrophy in HIV-infected subjects receiving HAART for atleast 6 months was 15.9\%. Lipoatrophy was $9.1 \%$ and lipohypertrophy was $6.8 \%$. The estimated prevalence of overall lipodystrophy in this study was small as compared to reports from other African countries (Diero et al., 2007), (Mutimura, et al., 2007)(16). Similar large studies undertaken in Africa reported the prevalence of lipodystrophy to be between 20.5\%-42.9\% (Diero et al., 2007(7), Mutimura et al., 2007(16) and George, et al., 2009)(11). This wide difference in prevalence levels from our study is attributable to differences in the definition of lipodystrophy (subjective or objective, patient report and/or physical examination, inclusion of mild form in the assessment), the study design and duration and type of treatment regimens used.

In a recently published study from Rwanda, the prevalence of mild to severe lipodystrophy in patients receiving HAART for at least 6 months was 34\% (Mutimura, et al., 2007)(16). A similar study conducted in Senegal reported a $31.1 \%$ prevalence of moderate to severe lipodystrophy (Mercier et al., 2009)(14). A report from Western Kenya found $20.5 \%$ subjects with lipodystrophy identified by physician's examination (Diero, et al., 2007)(7). A longitudinal study in South African patients reported a higher prevalence of lipodystrophy (42.9\%) when compared with other African studies (George et al., 2009)(11). 


\section{Factors associated with lipodystrophy Host factor}

In the current study female subjects had a greater prevalence of lipodystrophy than male subjects, as cited in a previous study (Mutimura, et al., 2007). It is not known whether this is attributed to gender-related physiologic differences.

A similar study from Rwanda indicated that male subjects are associated with a lower prevalence of lipodystrophy (Mutimura, et al., 2007)(16). A study from Senegal found no gender differences in the prevalence of lipodystrophy (Mercier et al., 2009)(14).

No significant association was observed between age, CD4 count, stage of disease and lipodystrophy. These findings were consistent with other studies with respect to identified factors which are associated with lipodystrophy; whereas inconsistency was observed in most reported factors in other studies.

One systematic review reported that older age (older than 40 years of age), female sex and low nadir CD4 cell count have all been identified as risk factors for lipodystrophy. Lipodystrophy is more severe in patients with a baseline CD4 cell count less than 350 cells/mm3 (Baril et al., 2005)(4).

\section{Treatment factors}

In the current study, no significant association existed between prevalence of lipodystrophy and types of HAART regimens. Our study revealed that longer duration on HAART had an increased risk of overall lipodystrophy and isolated lipoatrophy. In support to our finding, the duration of antiretroviral therapy, especially if longer than two years, was found to be an important risk factor for the development of lipodystrophy (Carr, et al., 1998) (6).

\section{Life style factors}

Engaging in lighter work intensity had an increased prevalence of overall lipodystrophy, isolated lipoatrophy and lipohypertrophy. Though the method for assessment of physical activity was different, our finding was consistent with this Australian study (Miller, et al., 2003)(15).

\section{Lipodystrophy as a factor}

Our study revealed that lipodystrophic subjects had higher prevalence of diabetes mellitus than non lipodystrophic subjects. In this study prevalence of diabetes mellitus was $4.6 \%$ in lipodystrophic subjects. From the phenotypes of lipodystrophy, lipohypertrophy and lipoatrophy were positively associated with diabetes mellitus, while only lipohypertrophy was associated with hypertension. In another study $7 \%$ of patients who had clinical evidence of fat redistribution syndrome had diabetes mellitus (Hadigan, et al., 2001).

In the present study it was observed that hypertension was not influenced by the presence or absence of overall lipodystrophy. The prevalence of hypertension in lipodystrophic subjects was $3.4 \%$ and in non lipodystrophic subjects was $12.5 \%$. One clinical trial conducted in Italy revealed that prevalence of systolic or diastolic hypertension was $19.8 \%$ at baseline in consecutive lipodystrophic patients attending metabolic clinics (Guaraldi, et al., 2006). The present study showed that lipohypertrophy predicts the presence of hypertension.

\section{Prevalence of other risk factors of CVD}

The participants of the present study were different in some health related behaviors from the participants of other studies. There were very little number of subjects $(1.1 \%)$ who were smoking cigarettes or drinking alcohol. The habit of regular physical activity was reported in $9.1 \%$ of subjects. In a study by Cheng and coworkers where the effect of alcohol on lipodystrophy was examined, $66 \%$ of the participants reported at least one moderate to heavy alcohol drinking (Cheng, et al., 2009). Another study reported that, $43.5 \%$ were smokers, $43.9 \%$ subjects were drinking alcohol at varying amounts and $37.7 \%$ of the subjects engaged in moderate to intense physical activity (Guaraldi, et al., 2006). A study from Swiss HIV cohorts conducted to determine the prevalence of cardiovascular risk factors in HIV positive individuals revealed that more than 50\% of HIV individuals were smokers (Glass, et al., 2004).

\section{Conclusion}

For HIV-infected patients receiving treatment with ART, the risk for CVD may be significantly greater than that for the general population and may increase with each year of ART exposure. Recent cohort and database studies suggest that cardiovascular events substantially contribute to mortality in HIV-infected patients receiving successful highly active antiretroviral therapy (HAART) (Aoun and Ramos, 2000)(2). Lipodystrophy syndrome has severe health consequences, as it may be responsible for stigma, reduced adherence to antiretroviral treatment, and increased risk of cardiovascular diseases (CVD) (Duran, et al., 2001)(8). Whether the data obtained in the present study are applicable to all HIV subjects receiving ART is a matter of debate. If 
the characteristics of the subjects are similar to the subjects of this study, these findings could also represent other HAART receiving HIV positives.

\section{References}

[1] Andrew, M., et al., (2003). "HIV-related lipodystrophy and related factors." ELSEVIER 174

[2] Aoun, S. and E. Ramos, (2000). "Hypertension in the HIV-infected patient." Curr Hypertens Rep 2: 478-81.

[3] Baecke, J., et al., (1982). " A short questionnaire for the measurement of habitual physical activity in epidemiological studies." Am J Clin Nutr 36: 936-942.

[4] Baril, J.G., et al., (2005). "HIV-associated lipodystrophy syndrome:A review of clinical aspects." C J Infec Dis Med Microbiol 16(4).

[5] Carr, A., et al., (2003). "An objective case definition of lipodystrophy in HIV-infected adults: a case-control study HIV." Lancet 361: $726-735$.

[6] Carr, A., et al., (1998). "A Syndrome of peripheral lipodystrophy, hyperlipidemia and insulin resistance in patients receiving HIV protease inhibitors." AIDS 12: F51-8

[7] Cheng, D. M. et al., (2009). "Alcohol Consumption and Lipodystrophy in HIV-infected Adults with Alcohol Problems." Alcohol 43(1): 65-71.

[8] Diero, L. O. et al., (2007). "Lipodystrophy in HIV infected patients on long term Antiretroviral therapy in western Kenya."

[9] Duran, S. et al., (2001). "Failure to maintain long-term adherence to highly active antiretroviral therapy: the role of lipodystrophy." AIDS 15: 2441-2444.

[10] FMOH, (2009). Guidelines for management of opportunistic infections and antiretroviral treatment in adolescents and adults in Ethiopia, Hapco.

[11] FMOH, (2005). AIDS in Ethiopia, sixth report.

[12] George, J. A. et al., (2009). "A Longitudinal Study of the Changes in Body Fat and Metabolic Parameters in a South African Population of HIV-Positive Patients Receiving an Antiretroviral Therapeutic Regimen Containing Stavudine." AIDS RESEARCH AND HUMAN RETROVIRUSES 25(8).

[13] Gibson, R. S. (2005). Principles of Nutritional Assessment. New York, Oxford University Press.

[14] Glass, T. et al., (2004). Prevalence of cardiovascular risk factors in HIV-infected individuals: the Swiss HIV Cohort Study. Int Conf AIDS. Bangkok, Thailand, Basel Institute for Clinical Epidemiology.

[15] Guaraldi, G. et al., (2006). "Multidisciplinary Approach to the Treatment of Metabolic and Morphologic Alterations of HIV-Related Lipodystrophy." HIV clinical trials 77(3): 97-106.

[16] Hadigan, C. (2003). "Dietary Habits and Their Association with Metabolic Abnormality in Human Immunodeficiency VirusRelated Lipodystrophy." Clinical Infectious Diseases 37(suppl 2): S101-4

[17] Hadigan, C. et al., (2001). "Metabolic Abnormalities and Cardiovascular Disease Risk Factors in Adults with Human Immunodeficiency Virus Infection and Lipodystrophy." Clinical Infectious Diseases 32: 130-9.

[18] Mercier, S. et al., (2009). "Lipodystrophy and Metabolic Disorders in HIV-1-Infected Adults on 4- to 9-Year Antiretroviral Therapy in Senegal: A Case-Control Study." J Acquir Immune Defic Syndr 51(2): 224-230.

[19] Miller, J. et al., (2003). "HIV lipodystrophy: prevalence, severity, and correlates of risk in Australia." HIV Medicine 4: $293-301$.

[20] Mutimura, E. et al., (2007). "Metabolic Function and the Prevalence of Lipodystrophy in a Population of HIV-Infected African Subjects Receiving Highly Active Antiretroviral Therapy." J Acquir Immune Defic Syndr 46(4).

[21] Perloff, D. et al., (1993). "Human Blood Pressure Determination by Sphygmomanometry." Circulation 88: $2460-2470$.

[22] Tien, P. C. and C. Grunfeld, (2004). "What is HIV-associated lipodystrophy? Defining fat distribution changes in HIV infection." HIV infection and AIDS 17(1): 27-32.

[23] WHO (2003). "Report of the Expert Committee on the Diagnosis and Classification of Diabetes Mellitus." DIABETES CARE $26 \mathbf{s}$ 1. 